\title{
Automation of Predictive Maintenance Using Internet of Things (IoT) Technology at University-Based O\&M Project
}

\author{
James Ryan Fernandez, Yogi Tri Prasetyo, Satria Fadil Persada, and A. A. N. Perwira Redi
}

\begin{abstract}
Predictive Maintenance can be defined as a type of advanced maintenance that detects the onset of system degradation allowing causal stressors to be eliminated or controlled prior to any significant deterioration in component physical state. Thru Internet of Things (IoT) Technology, automation, and implementation of Predictive Maintenance are possible. The purpose of this study is to propose the implementation of Predictive Maintenance using IpT Technology at University-based Operation \& Maintenance Project that aims to transform the current Key Performance Indicator (KPI) of PM to CM Ratio from 80:20 to 90:10. Six Sigma DMAIC Methodology and Data-Driven Predictive Maintenance Planning Framework were utilized as the methodology of this research. Research's results show that KPI, 90:10 (PM to CM Ratio) is achievable and maintenance cost can significantly reduce from $25 \%$ to $30 \%$. Other valuable benefits are return of investment $(\mathbf{1 0 X})$, elimination of breakdown (70 $75 \%)$, reduction in downtime $(35 \%-45 \%)$ and increase of production $(20 \%-25 \%)$. The proposed concept can be utilized in other industries to achieve high customer satisfaction percentages, sustainable operations, fault prediction, and online monitoring using PC or mobile applications.
\end{abstract}

Index Terms - Predictive maintenance, internet of things (IoT) technology, six sigma DMAIC methodology, data-driven predictive maintenance planning framework.

\section{INTRODUCTION}

Predictive Maintenance is a type of maintenance methodology that involves monitoring the health of an asset [1]-[10]. Asset's health is monitored in order to detect incipient failures and eventual degradation based on detection trends of component conditions using historical data [1]-[3], so that early action can be taken [4]. Thru Internet of Things (IoT) Technology, automating predictive maintenance can be acquired and implemented [5].

Internet of Things as part of an emerging technology platform in Industrial 4.0 was described as intelligent connectivity of smart devices by which objects can sense from one another and communicate using an internet network

Manuscript received January 13, 2021; revised February 24, 2021. This work was supported by the Mapúa University Directed Research for Innovation and Value Enhancement (DRIVE).

James Ryan Fernandez and Yogi Tri Prasetyo are with the School of Industrial Engineering and Engineering Management, Mapúa University, Philippines (e-mail: jamesryanfernandez.jrf@gmail.com, ytprasetyo@mapua.edu.ph).

Satria Fadil Persada is with the Business Management Department, Institut Teknologi Sepuluh Nopember (ITS), Surabaya, Indonesia (e-mail: satriafp@gmail.com).

A. A. N. Perwira Redi is with Bina Nusantara University, Jakarta, Indonesia (e-mail: wira.redi@binus.edu).
[8]. Internet network is a medium for billions of devices as the IoT, new paradigm quickly grows [2]. IoT has several applications like smart transportation, smart farming, smart health, smart cities, smart homes, energy management and facilities management [1]-[3].

Facilities Management (FM) Industry in Saudi Arabia has not yet adapted to predictive maintenance associated with IoT Technology despite of various benefits that may be achieved such as real-time asset condition monitoring, energy efficient monitoring and control without human intervention, to analyze and process machine faults in real-time, and minimization of total operational costs [7]. However, various factors are to be considered before commencing the implementation like IoT Sensor, Data, Centralized Data Processing Platform, Cloud Servers, Network, Software, Mobile Application and Information Visualization [7]-[9]. Information Visualization specifically Predictive Analytics and Prescriptive Analytics are the key features of these concepts enabling for the maintenance group to ease the decision making in providing solution to possible asset failure and to avoid its repetition [11]-[13]. Moreover, operational logic, facility conditions, live data streams, set points, control parameters, alarms, events, and trend logs are necessary for data collection [4].

The purpose of this study is to propose of implementation of Predictive Maintenance supported by IoT Technology at University-based O\&M Project guided by Six Sigma DMAIC Methodology [14]-[17] and Data-driven Predictive Maintenance Planning Framework [4]. Aiming to transform the current Key Performance Indicator of PM to CM Ratio from 80:20 to 90:10 that will lead to customer satisfaction, sustainable operations, fault prediction, and online monitoring using $\mathrm{PC}$ or mobile application [8].

The rest of this paper is organized as follows. Section II covers the methodology for implementation of Predictive Maintenance using IoT Technology guided by DMAIC approach and Planning Framework. Section III presents the results after application of concepts and methodology. Then, Section IV will discuss the findings in details and comparison with the related studies. Lastly, conclusion and recommendation for other studies are provided in Section V.

\section{Methodology}

This study was based on Corrective Maintenance and Preventive Maintenance 2019 data retrieved from Computer Maintenance Management System (CMMS) at KSAU-HS O\&M Project aiming to improve the set KPI from 80:20 to 
90:10 (PM to CM Ratio). This research employs the concepts of Predictive Maintenance using Internet of Things (IoT) Technology utilizing the Six Sigma DMAIC Methodology and Data-driven Predictive Maintenance Planning Framework for implementation [4].

\section{A. Define Phase}

Table I shows the number of PM and CM generated on CMMS in the year 2019. It addressed the overall performance of Operation \& Maintenance of the university project. Indicating that Preventive Maintenance (PM) generated 96,343 work orders while our Helpdesk received 18,201 Corrective Maintenance (CM) Requests from end-user resulting in 84:16 (PM to CM Ratio).

TABLE I: PM AND CM COUNT PER MONTH WITH PM TO CM RATIO (2019)

\begin{tabular}{|c|c|c|c|}
\hline Month & PM & CM & PM to CM Ratio \\
\hline January & 6338 & 1380 & $82: 18$ \\
\hline February & 9975 & 1379 & $88: 12$ \\
\hline March & 8532 & 1558 & $85: 15$ \\
\hline April & 8909 & 1693 & $84: 16$ \\
\hline May & 6738 & 1331 & $84: 16$ \\
\hline June & 6861 & 1251 & $85: 15$ \\
July & 8731 & 1376 & $86: 14$ \\
\hline August & 9786 & 1343 & $88: 12$ \\
\hline September & 9189 & 1792 & $84: 16$ \\
\hline October & 6962 & 1568 & $82: 18$ \\
\hline November & 7323 & 1700 & $81: 19$ \\
\hline December & 6999 & 1830 & $79: 21$ \\
\hline Grand Total & 96343 & 18201 & $84: 16$ \\
\hline
\end{tabular}

\section{B. Measure Phase}

In the Measure Phase, we used Performance Dashboard (Fig. $1 \& 2$ ) to quantify the percentage of asset-related and non-asset related CM Work Orders to verify if possible to achieve the 90:10 (PM to CM Ratio) using automated Predictive Maintenance and IoT Technology. The figures show that $72 \%$ of CM Work Orders relating to assets and can be resolved using the proposed concepts.

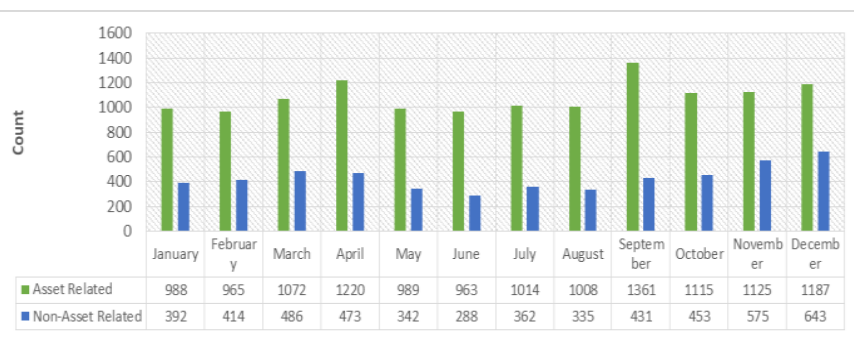

Fig. 1. Asset Related \& non-asset related (2019).

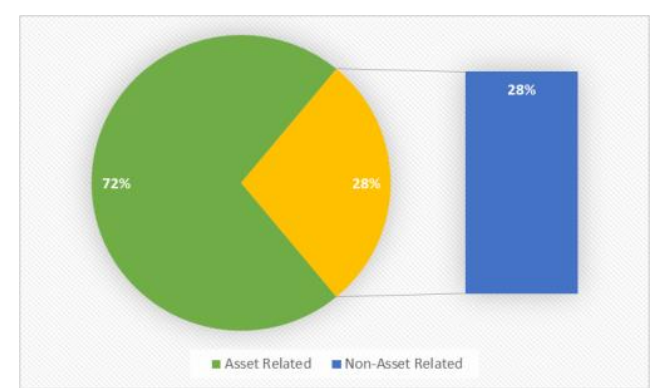

Fig. 2. Percentage ratio between asset related \& non-asset related W.O.

\section{Analyze Phase}

Fish Bone Diagram (Fig. 3) was performed to analyze the cause of $72 \%$ Asset Related Corrective Maintenance Work Orders from the perspective of process / methods, manpower, system, and performance. The 8-root cause are possible for elimination by introduction of automated Predictive Maintenance using IOT Technology in KSAU-HS O\&M Project.

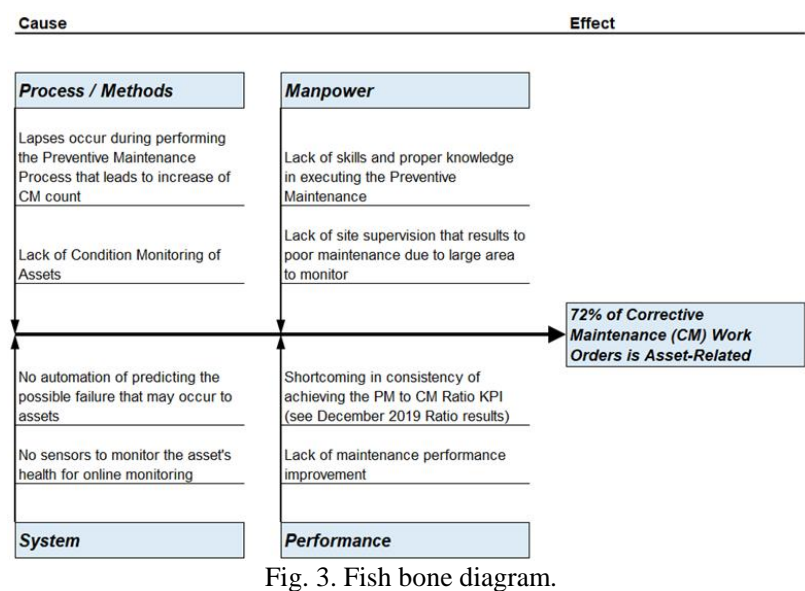

\section{Improve Phase}

Data-driven Predictive Maintenance Planning Framework proposed by Cheng et al. [4] and recommended layers for IoT implementation by Daissaoui et al., [1] were utilized in building the Predictive Maintenance Process Flow Chart (Fig. 4) and the System Design Process Chart (Fig. 5). These two charts represents the Improve Phase aiming for the elimination of $72 \%$ Asset Related Corrective Maintenance Work Orders from its total count.

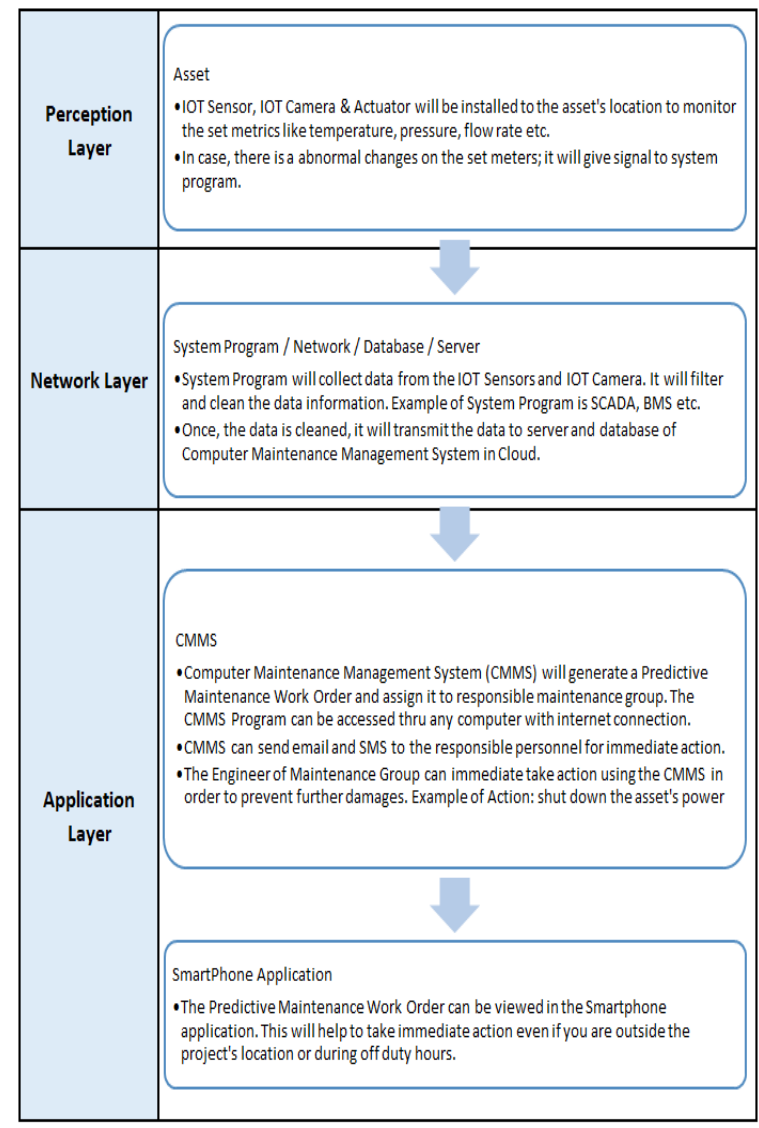

Fig. 4. Predictive maintenance process flow chart.

\section{E. Control Phase}

Table II exhibits the Process Control Plan during Control 
Phase mitigating the control methods and response for every control items in the Process Chart.

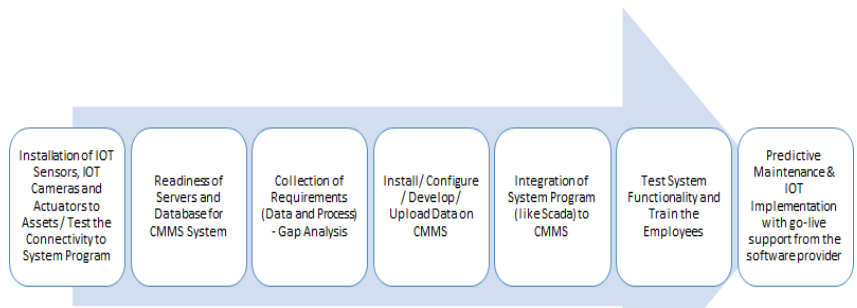

Fig. 5. System design process chart.

TABLE II: PROCESS CONTROL PLAN

\begin{tabular}{|c|c|c|c|c|c|c|}
\hline Layers & Control them [Bsed on Process Chatt) & Control Nethoods & Frequency & Responsibitity & Requirement & Response Plan \\
\hline \multirow{4}{*}{ Perception Lajer } & Data Collected from Sersors & Auvit Data Efficiency & Montly & IT Engineer & $100 \%$ Accurate & \multirow{4}{*}{$\begin{array}{l}\text { Technical Consultant will valdidates the } \\
\text { maintenance of datat, devices \& accessonie } \\
\text { conducted by resporsibible engineer }\end{array}$} \\
\hline & IOT Sersor & Auot Dewice Efficicency & Montly & IT Engineer & $100 \%$ Working & \\
\hline & LOT Camera & Audit Dewive Efficiency & Montly & IT Engineer & $100 \%$ Working & \\
\hline & Actuator & Auvit Device efficicency & Montly & $1 T$ Engineer & $100 \%$ Working & \\
\hline \multirow{4}{*}{ Network loger } & Network & Monitoring & Dally & IT Network Team & $100 \%$ Working & \multirow{4}{*}{$\begin{array}{l}\text { Technical Consultant will review the } \\
\text { - effiency of netwuort, databasse, severe and } \\
\text { spstem progam. }\end{array}$} \\
\hline & Databosese & Monitoring & Dally & ITSpstem Team & $100 \%$ Working & \\
\hline & Sener & Monitoring & Dally & ITystem Team & $100 \%$ Working & \\
\hline & System Program & Monitoring & Dally & ITSystem Team & $100 \%$ Working & \\
\hline \multirow{3}{*}{ Application Layer } & CMNS & Daly Review & Dally & Administrator & $100 \%$ Working & \multirow{2}{*}{$\begin{array}{l}\text { Business Consultant will review the data } \\
\text { output from CMMS and Smartphone }\end{array}$} \\
\hline & Smartphone Application & Daly Review & Dally & Administrator & $100 \%$ Working & \\
\hline & Mairtenance Group Action & Audit Performance & Dally & Mangegenent & 95\% Performance Effency & $\begin{array}{l}\text { Work Control Center Manager will audit the } \\
\text { performance of each department }\end{array}$ \\
\hline
\end{tabular}

Live graphical analytics and reporting dashboards (Fig. 6) are utilized in the Control Phase to monitor the performance of operation and maintenance.

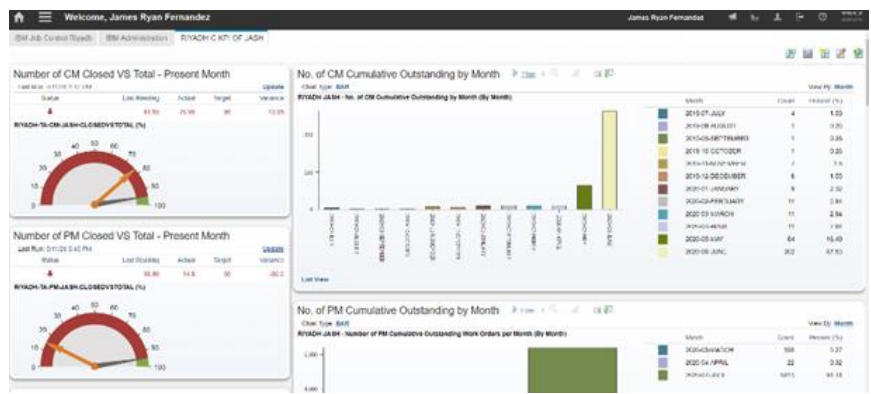

Fig. 6. Graphical analytics and reporting dashboard (example).

\section{RESULTS}

This section covers the results from the application of Predictive Maintenance using the Internet of Things (IoT) Technology at University-based Operation \& Maintenance Project utilizing the Six Sigma DMAIC Methodology and Data-driven Predictive Maintenance Planning Framework [4].

\section{A. CM Count Reduction}

The total Corrective Maintenance Work Orders that generated from the year 2019 was 18,201. Out of the total CM count, 13,007 were related to asset failure. After application of Predictive Maintenance, $72 \%$ is expected to be reduced or eliminated from the total CM Work Orders. This will result in a new count of CM Work Orders which is 5,194.

\section{B. Improved Key Performance Indicator}

The goal of this study is to transform the current Key Performance Indicator of PM to CM Ratio from 80:20 to 90:10. Based on the results from 2019 records, the goal of this paper was achieved (refer to Table IV) and transformed the PM to CM Ratio from 84:16 to 95:05. The changes show that PM Work Orders is composed of $95 \%$ while CM Work Orders are only $5 \%$. This indicates an excellent operation \& maintenance performance that surpasses the new set Key Performance Indicator.

TABLE III: NEW CORRECTIVE MAINTENANCE COUNT AFTER APPLICATION OF PREDICTIVE MAINTENANCE

\begin{tabular}{|c|r|r|r|r|}
\hline Month & CM Old Count & CM-Asset-Related & CM New Count & \% Total Reduction \\
\hline January & 1,380 & 988 & 392 & $72 \%$ \\
\hline February & 1,379 & 965 & 414 & $70 \%$ \\
\hline March & 1,558 & 1,072 & 486 & $69 \%$ \\
\hline April & 1,693 & 1,220 & 473 & $72 \%$ \\
\hline May & 1,331 & 989 & 342 & $74 \%$ \\
\hline June & 1,251 & 963 & 288 & $77 \%$ \\
\hline July & 1,376 & 1,014 & 362 & $74 \%$ \\
\hline August & 1,343 & 1,008 & 335 & $75 \%$ \\
\hline September & 1,792 & 1,361 & 431 & $76 \%$ \\
\hline October & 1,568 & 1,115 & 453 & $71 \%$ \\
\hline November & 1,700 & 1,125 & 575 & $66 \%$ \\
\hline December & 1,830 & 1,187 & 643 & $65 \%$ \\
\hline \hline Grand Total & 18,201 & 13,007 & 5,194 & $72 \%$ \\
\hline
\end{tabular}

TABLE IV: NEW KPI (PM TO CM RATIO)

\begin{tabular}{|c|c|c|}
\hline Month & Old PM to CM Ratio & New PM to CM Ratio \\
\hline January & $82: 18$ & $94: 06$ \\
\hline February & $88: 12$ & $96: 04$ \\
\hline March & $85: 15$ & $95: 05$ \\
\hline April & $84: 16$ & $95: 05$ \\
\hline May & $84: 16$ & $95: 05$ \\
\hline June & $85: 15$ & $96: 04$ \\
\hline July & $86: 14$ & $96: 04$ \\
\hline August & $88: 12$ & $97: 03$ \\
\hline September & $84: 16$ & $96: 04$ \\
\hline October & $82: 18$ & $94: 06$ \\
\hline November & $81: 19$ & $93: 07$ \\
\hline December & $79: 21$ & $92: 08$ \\
\hline \hline Grand Total & $84: 16$ & $95: 05$ \\
\hline
\end{tabular}

\section{Cost Benefit Analysis}

According to independent surveys conducted by (Sullivan et al., 2010), the initiation of a functional predictive maintenance program can reduce the maintenance costs from $25 \%$ to $30 \%$. Operation and Maintenance Budget allotted to the main contractor by University-based O\&M Project for 5 years is SAR 650,000,000.00. In this regards, applying cost benefit analysis into minimum and maximum cost reduction percentage (Table V \& VI) will help to gain further insight to its financial benefit:

TABLE V: COST BENEFIT ANALYSIS (25\%)

\begin{tabular}{|c|c|c|c|}
\hline Cost & Amount (SAR) & Benefit & Amount (SAR) \\
\hline $\begin{array}{c}\text { University Operation \& Maintenance Budget } \\
\text { for } 5 \text { years (KSA) }\end{array}$ & SAR 650,000,000.00 & $\begin{array}{c}\text { Predictive Maintenance } \\
\text { with ITT Technology } \\
\text { Implementation }\end{array}$ & $\begin{array}{c}\text { SAR 650,000,000.00 x } \\
25 \%=\text { SAR } \\
162,500,000.00\end{array}$ \\
\hline \multicolumn{2}{|c|}{ Total Cost } & Total Benefit & SAR 162,500,000.00 \\
\hline \multicolumn{2}{|c|}{ SAR $650,000,000.00$} & Tenefit Ratio & $01: 25$ \\
\hline
\end{tabular}

The new total cost is SAR 487,500,000.00 after deducting the minimum maintenance costs reduction $(25 \%)$.

TABLE VI: COST BENEFIT ANALYSIS (30\%)

\begin{tabular}{|c|c|c|c|}
\hline Cost & Amount (SAR) & Benefit & Amount (SAR) \\
\hline $\begin{array}{c}\text { University Operation \& Maintenance Budget } \\
\text { for 5 years (KSA) }\end{array}$ & SAR 650,000,000.00 & $\begin{array}{c}\text { Predictive Maintenance } \\
\text { with IOT Technology } \\
\text { Implementation }\end{array}$ & $\begin{array}{c}\text { SAR 650,000,000.00 x } \\
30 \%=\text { SAR } \\
195,000,000.00\end{array}$ \\
\hline Total Cost & SAR 650,000,000.00 & Total Benefit & SAR 195,000,000.00 \\
\hline \multicolumn{2}{|c|}{ Cost-Benefit Ratio } & $01: 30$ \\
\hline
\end{tabular}


The new total cost is SAR 455,000,000.00 after deducting the minimum maintenance costs reduction (30\%).

\section{Other Benefits}

Other benefits after application of Predictive Maintenance according to Sullivan et al., 2010:

1) Return of investment: 10 times

The estimated total cost of predictive maintenance program is SAR 15,000,000.00. Based on the Cost Benefit Analysis, the implementation cost had resulted to return of investment (ROI) of 10 to 13 times more.

2) Elimination of breakdown: $70 \%$ to $75 \%$

The elimination of breakdown reached up to $72 \%$ based on data collection.

3) Reduction in downtime: $35 \%$ to $45 \%$

4) Increase in production: $20 \%$ to $25 \%$

\section{DISCUSSION}

Results of application of Predictive Maintenance with Internet of Things (IoT) Technology utilizing the Sig Sigma DMAIC Methodology and Data-driven Predictive Maintenance Planning Framework of Cheng et al. [4] improved the Key Performance Indicator from 84:16 to 95:05 (PM to CM Ratio) due to elimination of $72 \%$ Corrective Maintenance Asset-related Work Orders.

Maintenance cost reduction amounted to SAR $162,500,000.00$ based on minimum reduction cost percentage of $25 \%$ and it may extends up to SAR $195,000,000.00$ in $30 \%$ cost reduction. Similar to study conducted by Rohit Dhall et al. [6] for an IoT-based predictive connected car maintenance approach; the total maintenance cost reduction resulted to $30 \%$. In addition, other benefits were achieved such as multiple return of investment, elimination of breakdown, reduction in downtime and increase in production which is comparable to previous studies [7], [10], [18]-[21].

Asset health was addressed through the real-time monitoring using PC and mobile, fault prediction, energy efficient monitoring and control without human intervention, condition-based monitoring, and maintenance analytics and reporting dashboard [1], [6], [7], [9]. The results concluded that application of Predictive Maintenance with Internet of Things (IoT) Technology delivered compelling benefits and improvements in the operation and maintenance of University-based Project.

Moreover, an idea of integration of artificial intelligence to current solution can bring-out an AI Assistant to maintenance team. The possibility of seeking a technical advice from an AI Assistant to resolve an asset failure based on accumulated data from history, IoT sensors and predictive modelling can ease the work, increase accuracy and efficiency of a technician or an engineer without prior knowledge of a repair situation. This also ensures that the repair is completed right at the first time. In addition, an AI Assistant is expected to continuously learn and support the operation and maintenance of a project.

\section{CONCLUSION}

This research paper presented the effectiveness of automating Predictive Maintenance using Internet of Things (IoT) Technology at University-based O\&M Project in terms of improving key performance indicator (PM to CM Ratio), reduction of received Corrective Maintenance Work Orders, maintenance reduction cost $(25 \%-30 \%)$, return of investment (10 to $13 \mathrm{X})$, elimination of breakdown (70 - 75\%), reduction in downtime $(35 \%-45 \%)$ and increase of production $(20 \%-25 \%)$ utilizing the Six Sigma DMAIC Methodology and Data-driven Predictive Maintenance Planning Framework of Cheng et al. [4].

\section{A. Limitations}

Internet of Things (IoT) Technology are one of the emerging technology platform in Industrial 4.0 and using this technology in automating the Predictive Maintenance brings out the maximum potential of the proposed maintenance methodology in the O\&M Project. However, there are other technologies that can be explored and utilized in implementing Predictive Maintenance such as Artificial Intelligence. More advanced technologies can be expected to rise in the upcoming years that will lead for huge improvement in the field of Facilities Management.

\section{B. Future Research}

The researcher suggested exploring more detailed step by step procedures on application of Internet of Things (IoT) Technology in Predictive Maintenance in the current study that incorporates review of literatures from previous studies to view research gaps, a customized predictive maintenance framework with defined technical modules, a process flow diagram that compares the before and after implementation, asset's health dashboard and other benchmarks to support the study. The applicability of combination of Internet of Things (IoT) Technology and Artificial Intelligence in the operation and maintenance can be also examined in Facility Management Projects in order to acquire more beneficial impacts in the organization, society, and environment.

\section{CONFLICT OF INTEREST}

The authors declare no conflict of interest.

\section{AUTHOR CONTRIBUTIONS}

JRF conducted the research, analyzed the data, and prepared the manuscript; YTP supervised; SFP and AANPR reviewed and edited the manuscript; all authors had approved the final version.

\section{ACKNOWLEDGMENT}

The authors would like to thank Mapúa University Directed Research for Innovation and Value Enhancement (DRIVE) for funding this study.

\section{REFERENCES}

[1] A. Daissaoui, A. Boulmakoul, L. Karim, and A. Lbath, "IoT and big data analytics for smart buildings: A survey," Procedia Computer Science, vol. 170, pp. 161-168, 2020.

[2] P. Killeen, B. Ding, I. Kiringa, and T. Yeap, "IoT-based predictive maintenance for fleet management," Procedia Computer Science, vol. 151, pp. 607-613, 2019

[3] S. Tedeschi, J. Mehnen, N. Tapoglou, and R. Roy, "Secure IoT devices for the maintenance of machine tools," Procedia CIRP, vol. 59, pp. 150-155, 2017. 
[4] J. C. Cheng, W. Chen, K. Chen, and Q. Wang, "Data-driven predictive maintenance planning framework for MEP components based on BIM and IoT using machine learning algorithms," Automation in Construction, vol. 112, p. 103087, 2020.

[5] M. Akatsu, "Social innovation business through value co-creation with customers powered by Lumada: A case study of Hitachi Ltd.," Business Innovation with New ICT in the Asia-Pacific: Case Studies, pp. 59-83, 2020.

[6] R. Dhall and V. K. Solanki, "An IoT based predictive connected car maintenance approach," International Journal of Interactive Multimedia and Artificial Intelligence, vol. 4, no. 3, p. 16, 2017.

[7] A. Xenakis, A. Karageorgos, E. Lallas, A. E. Chis, and H González-Vélez, "Towards distributed IoT/cloud based fault detection and maintenance in industrial automation," Procedia Computer Science, vol. 151, pp. 683-690, 2019.

[8] R. C. Parpala and R. Iacob, "Application of IoT concept on predictive maintenance of industrial equipment," MATEC Web of Conferences, vol. 121, p. 02008, 2017.

[9] L. Trotter, M. Harding, M. Mikusz, and N. Davies, "IoT-enabled highway maintenance: Understanding emerging cybersecurity threats," IEEE Pervasive Computing, vol. 17, no. 3, pp. 23-34, 2018

[10] R. B. Shetty, "Predictive maintenance in the IoT era," Prognostics and Health Management of Electronics, pp. 589-612, 2018.

[11] S. Hönel, M. Ericsson, W. Löwe, and A. Wingkvist, "Using source code density to improve the accuracy of automatic commit classification into maintenance activities," Journal of Systems and Software, vol. 168, p. 110673, 2020.

[12] T. Strobach, C. Englert, D. Jekauc, and I. Pfeffer, "Predicting adoption and maintenance of physical activity in the context of dual-process theories," Performance Enhancement \& Health, vol. 8, no. 1, p. 100162,2020

[13] A.-Q. Gbadamosi, L. O. Oyedele, J. M. D. Delgado, H. Kusimo, L. Akanbi, O. Olawale, and N. Muhammed-Yakubu, "IoT for predictive assets monitoring and maintenance: An implementation strategy for the UK rail industry," Automation in Construction, vol. 122, p. 103486 2021.

[14] T. Chuenyindee and Y. T. Prasetyo, "Roller chains quality enhancement using six sigma and failure mode and effects analysis (FMEA)," in Proc. the 2020 2nd International Conference on Management Science and Industrial Engineering, 2020.

[15] T. Chuenyindee and A. Vanichchinchai, "Waste reduction of powder color in coating process of air conditioner parts," in Proc. the 2019 5th International Conference on Industrial and Business Engineering, 2019.

[16] Y. T. Prasetyo and F. C. Veroya, "An application of overall equipment effectiveness (OEE) for minimizing the bottleneck process in semiconductor industry," in Proc. 2020 IEEE 7th International Conference on Industrial Engineering and Applications (ICIEA), 2020.

[17] Y. T. Prasetyo and D. D. Salazar, "Polishing material effectiveness for vertical crown tip by lean six sigma DMAIC approach," in Proc. 2020 7th International Conference on Frontiers of Industrial Engineering (ICFIE), 2020

[18] A.-Q. Gbadamosi, L. O. Oyedele, J. M. D. Delgado, H. Kusimo, L. Akanbi, O. Olawale, and N. Muhammed-Yakubu, "IoT for predictive assets monitoring and maintenance: An implementation strategy for the UK rail industry," Automation in Construction, vol. 122, p. 103486, 2021.

[19] I. T. Christou, N. Kefalakis, A. Zalonis, J. Soldatos, and R. Bröchler, "End-to-end industrial IoT platform for actionable predictive maintenance," IFAC-PapersOnLine, vol. 53, no. 3, pp. 173-178, 2020.

[20] E. Ingemarsdotter, E. Jamsin, and R. Balkenende, "Opportunities and challenges in IoT-enabled circular business model implementation A case study," Resources, Conservation and Recycling, vol. 162, p. 105047,2020

[21] B. Farahani, F. Firouzi, and M. Luecking, "The convergence of IoT and distributed ledger technologies (DLT): Opportunities, challenges, and solutions," Journal of Network and Computer Applications, p. 102936, 2020.
Copyright $(2021$ by the authors. This is an open access article distributed under the Creative Commons Attribution License which permits unrestricted use, distribution, and reproduction in any medium, provided the original work is properly cited (CC BY 4.0).

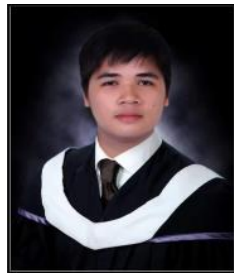

James Ryan Fernandez was born in Cavite, Philippines on January 17, 1993. He graduated with the bachelor of science in business administration major in management from CAP Colleges Foundation Inc. $\mathrm{He}$ is also a candidate of masters of engineering in industrial engineering from Mapua University in 2020. He is currently working as work control center manager at Zahran O\&M Company, Saudi Arabia. Previously, he worked as WCC engineer. His interests in research are related to quality engineering tools, facility management, predictive maintenance, internet of things, and big data analytics.

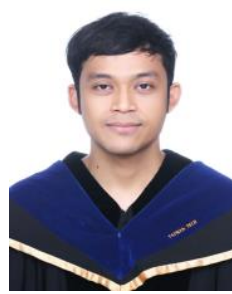

Yogi Tri Prasetyo is currently an associate professor in the School of Industrial Engineering and Engineering Management, Mapúa University, Philippines. He received a bachelor of engineering in industrial engineering from Universitas Indonesia (2013). He also studied for one year (2011-2012) at Waseda University, Japan, during his junior year as an undergraduate exchange student. He received an MBA (2015) and a Ph.D. (2019) from the Department of Industrial Management National Taiwan University of Science and Technology (NTUST), with a concentration in human factors and ergonomics. He was awarded as NTUST Outstanding Youth with a perfect GPA of 4.00. He has a wide range of research interests including human-computer interaction particularly related to eye movement, color optimization of military camouflage, strategic product design, usability analysis, and now he is currently doing accident analysis and prevention. $\mathrm{He}$ published several SCI journals in International Journal of Infectious Diseases, International Journal of Disaster Risk Reduction, Displays, Color Research and Application, Journal of Eye Movement Research, several non-SCI journals, and several conference proceedings. In addition, Dr.Yogi has contributed to several international conferences as co-chair, chair session, and even committee member with numerous best presentation awards.

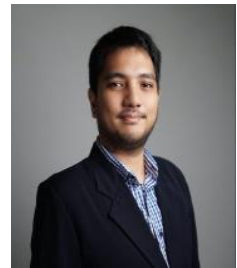

Satria Fadil Persada is a lecturer at the Business Management Department, Institut Teknologi Sepuluh Nopember (ITS), Surabaya, Indonesia. He received his bachelor degree from Information System Department, ITS. He continued his study and received his master and doctoral degree from Department of Industrial Management, National Taiwan University of Science and Technology (NTUST), Taipei, Taiwan. After completing his doctoral degree, he worked at Department of Business Management. Dr. Satria conducted a research on behavioral model, especially on psychological aspects that influence a person's intention when he was a doctor student at NTUST. Dr. Satria is now joining the Entrepreneurship and Small Medium Enterprsie (ESME) research lab in the Business Management Department. His research interest is studying the behavior of person's in the perspective of consumen and organizational. Dr Satria' research interest is also related to pro environmental behavior.

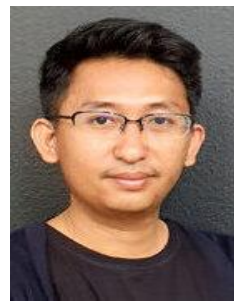

A. A. N. Perwira Redi is a lecturer in master of industrial engineering program at Bina Nusantara University, Indonesia. He achieved his doctoral degree at National Taiwan University of Science and Technology (NTUST). He has much experience in national and international research project related to logistics, supply chain, information system and many others. Dr. Perwira Redi has published several studies in SCI journals such as Applied Soft Computing, Computers \& Industrial Engineering, Computers \& Operation Research, Expert Systems with Applications, and Engineering Optimization. 